\title{
Acoustic emission signatures prior to snow failure
}

\author{
ACHILLE CAPELLI, ${ }^{1}$ INGRID REIWEGER, ${ }^{2}$ JÜRG SCHWEIZER ${ }^{1}$ \\ ${ }^{1}$ WSL Institute for Snow and Avalanche Research SLF, Davos Dorf, Switzerland \\ ${ }^{2}$ Department of Civil Engineering and Natural Hazards, Institute of Mountain Risk Engineering, \\ BOKU University of Natural Resources and Life Sciences, Vienna, Austria \\ Correspondence: Achille Capelli <achille.capelli@slf.ch>
}

\begin{abstract}
Snow slab avalanches are caused by cracks forming and propagating in a weak snow layer below a cohesive slab. The gradual damage process leading to the formation of the initial failure within the weak layer (WL) is still not entirely understood. To this end, we designed a novel test apparatus that allows performing loading experiments with large snow samples $\left(0.25 \mathrm{~m}^{2}\right)$ including a WL at different loading rates and simultaneously monitoring the acoustic emissions (AE) response. By analyzing the AE generated by micro-cracking, we studied the evolution of the damage process preceding snow failure. At fast loading rates, the exponent of the AE energy distribution ( $b$-value) gradually changed, and both the energy rate and the inverse waiting time increased exponentially with increasing load. These changes in AE signature indicate a transition from small to large events and an acceleration of the damage processes leading to brittle failure. For the experiments at slow loading rate, these changes in the AE signature were not or only partially present, even if the sample failed, indicating a different evolution of the damage process. The observed characteristics in AE response provide new insights on how to model snow failure as a critical phenomenon.
\end{abstract}

Keywords: avalanches, snow, snow mechanics, snow rheology

\section{INTRODUCTION}

To model the release of a dry-snow slab avalanche, it is essential to understand how failures in snow initiate and develop. Though we have a good conceptual understanding of the key processes involved in slab avalanche release (e.g. Schweizer and others, 2016), we still lack a detailed understanding of the first stage, the failure initiation process or in other words the gradual damage process leading to the nucleation of the initial failure. This initial failure can either be caused by an external, rapid, localized load such as a skier or an explosion, or form gradually from local heterogeneities due to slowly changing loading conditions and snow properties. Recent developments in modeling the failure behavior of snow aim to incorporate snow microstructural properties (e.g. Hagenmuller and others, 2014; Gaume and others, 2015). Detailed laboratory studies are needed to constrain and validate microstructural models of damage development and failure initiation in weak snow layers. There is still a lack of understanding with regard to their failure behavior, e.g. the failure envelope (Reiweger and others, 2015a), how damage develops into macroscopic cracks and how the loading rate affects the failure behavior.

Snow is a heterogeneous, highly porous material with strongly rate-dependent material properties. Under tension, at low loading rates, snow fails in ductile manner, while at high loading rates, it exhibits brittle failure (Narita, 1983). In displacement-controlled shear experiments, the ductileto-brittle transition was found to occur at strain rates of $10^{-4}$ to $10^{-3} \mathrm{~s}^{-1}$ (Fukuzawa and Narita, 1993; Schweizer, 1998). The rate-dependent behavior was explained by the competition between the damage process and healing due to sintering (de Montmollin, 1982; Schweizer, 1999; Reiweger and others, 2009). At slow rates, bond breaking is assumed to be compensated by re-bonding or sintering, whereas at high rates, the damage process dominates and leads to brittle failure.
The observed failure behavior in snow was also explained to result from the viscous deformation of the ice matrix (creep) and a viscous-to-brittle transition in ice (Kirchner and others, 2001). Moreover, ice creep can cause relaxation of local load concentrations preventing the initiation of a macroscopic failure, and can be considered as a further mechanism contrasting the damage process. Most probably, a combination of the different mechanisms is involved. We will refer to healing in the rest of the article as the combination of mechanisms compensating the damage process.

Microscopic cracking causes the release of elastic energy in the form of elastic waves, known as acoustic emissions (AE). Recording the AE allows studying the progressive failure in a non-destructive way. It is an established technique for the analysis of the damage process and the detection of failure at an early stage (Grosse and Ohtsu, 2008). The AE technique is employed for different heterogeneous materials such as concrete (Ohtsu, 1996), wood (Bucur, 2006), rocks (Lockner, 1993) or composite materials (Guarino and others, 1998) at the laboratory scale as well as at larger scale, e.g. stone cliffs (Amitrano and others, 2005) or glaciers (Faillettaz and others, 2011). The failure of disordered materials, such as snow, can also be interpreted as a critical phenomenon with a phase transition from a stable to an unstable phase. The unstable phase is characterized by micro-cracks growing and the correlated damage process culminating in macroscopic failure when a critical density of the damage is reached (Johansen and Sornette, 2000).

Previous studies on AE of heterogeneous materials have reported an acceleration of the damage, and of the resulting $\mathrm{AE}$, prior to macroscopic failure and the existence of several AE precursory signals (e.g. Guarino and others, 1998). Very similar characteristic features preceding failure were also 
found for statistical numerical models like fiber bundle and thermal fuse models (e.g. Girard and others, 2010).

One important parameter is the energy of the AE and its distribution. The energy of the AE usually follows a powerlaw distribution

$$
P(E) \sim E^{-b}
$$

where the exponent is usually referred to as the $b$-value (Guarino and others, 1998; Alava and others, 2006). A decrease of the $b$-value toward failure was reported for laboratory experiments (Lockner, 1993; Guarino and others, 1998) as well as for rock cliffs (Amitrano and others, 2005). A decreasing $b$-value means that the frequency of the large events increases. Furthermore, the decrease has been interpreted as an apparent change in the power-law exponent due to the fact that the energy follows a truncated power-law with diverging cut-off toward failure (e.g. Amitrano and others, 2005). The diverging cut-off theory is supported by the results of numerical simulations (Alava and others, 2006; Girard and others, 2010; Amitrano, 2012). For the failure of a hanging glacier, Faillettaz and others (2011) suggested the following $b$-value evolution: an initial stable state with power-law distribution of AE energy and constant $b$-value was followed by a phase with energy distribution diverging from the power-law. Close to failure, the power-law behavior recovered with high $b$-value. A second $\mathrm{AE}$ feature indicating an acceleration of the damage process is the increase of the energy release rate, which indicates an increase in size or frequency of the microscopic damage generating the $\mathrm{AE}$. A critical divergence following a power-law of the energy rate $E(t) \sim\left[\left(t_{\text {failure }}-t\right) / t_{\text {failure }}\right]^{K}$ toward the failure point $t_{\mathrm{c}}$ was observed for load-controlled laboratory experiments (Guarino and others, 1998) and for gravity-driven collapse of a limestone cliff (Amitrano and others, 2005). Johansen and Sornette (2000) observed a power-law increase of the energy rate with log-periodic modulation, which reveal intermittent acceleration and quiescence becoming more closely spaced while approaching failure. In general, a power-law divergence of the energy rate has been observed for load-controlled and constant load (creep) conditions (Guarino and others, 1998; Amitrano and others, 2005; Nechad and others, 2005; Amitrano and Helmstetter, 2006), whereas an exponential increase was reported for displacement-controlled experiments (Guarino and others, 1998; Salminen and others, 2002). Faillettaz and others (2011) analyzed the inverse waiting time (inverse of time lag between two $A E$ ) and observed increasing inverse waiting time toward failure indicating an acceleration of the damage process.

The power-law distribution of the energy is scale invariant, and therefore the $b$-value does not depend on the absolute value of the AE energy. Similarly, other AE features such as the change in time of the energy rate and the waiting time do not depend on the absolute values of $\mathrm{AE}$ amplitude. Hence, these features have the advantage that they are less sensitive to attenuation and material-sensor coupling.

Since the 1970s, several attempts were made to apply the $\mathrm{AE}$ technique in snow research. Field studies suggested a connection between increased AE activity and snowpack instability (Sommerfeld, 1977; St. Lawrence and Bradley, 1977; Gubler, 1979; Sommerfeld and Gubler, 1983; Watters and Swanson, 1987), whereas other authors reported that quiescent periods may be associated with avalanche activity
(Bowles and St. Lawrence, 1977; Sommerfeld, 1982). The results of early field studies are partly difficult to interpret due to different experimental set-ups, the different frequency ranges and technical limitations in the signal processing available at that time. St. Lawrence (1980) developed a relation describing the $\mathrm{AE}$ activity as a function of stress and strain for slow deformation of snow. More recently, Scapozza and others (2004) performed displacement-controlled compression experiments with homogeneous snow samples and observed high-frequency AE $(500 \mathrm{kHz})$ probably due to creep processes in the ice skeleton for strain rates $<2 \times 10^{-3} \mathrm{~s}^{-1}$ and lower frequency $\mathrm{AE}(30 \mathrm{~Hz})$ for strain rates $>2 \times 10^{-3} \mathrm{~s}^{-1}$, which they attributed to cracking. Moreover, Scapozza and others (2004) reported for low strain rates that the maximum of the $\mathrm{AE}$ activity corresponded to the yield point and observed the relation $\dot{\hat{N}}_{\text {peak }}=C \dot{\epsilon}^{\gamma}$ between the peak $\mathrm{AE}$ rate $\dot{\mathrm{N}}_{\text {peak }}\left(\right.$ hits s${ }^{-1}$ ) and the strain rate $\dot{\epsilon}$, with the parameter $C$ being temperature-dependent and $\gamma$ a constant. Reiweger and others (2015b) performed loadcontrolled experiments with layered snow samples including a weak layer $(\mathrm{WL})$ and observed an acceleration of the $\mathrm{AE}$ rate before failure as well as a decrease of the $b$-value very close to complete failure of the sample; they also found this $\mathrm{AE}$ behavior in case of partial failure of the sample. Datt and others (2015) reported for displacement-controlled compression of homogeneous samples a maximum of the $b$-value at the yield point for low strain rates, and for high strain rates, a decrease of the $b$-value at brittle fracture.

According to the current theories about the failure of heterogeneous materials (e.g. Johansen and Sornette, 2000), failure is the result of the interaction and growth of a multitude of spatially distributed microscopic cracks or damage. It is therefore important to study the damage process on samples of size comparable to the critical size $A_{\mathrm{C}}$ for the onset of crack propagation leading to dry snow slab avalanche release $\left(1 \mathrm{dm}^{2}<A_{c}<1 \mathrm{~m}^{2}\right.$; e.g. Schweizer and others, 2008); the generated AE may have different signatures from those obtained with smaller samples used in previous studies (Reiweger and others, 2015b). Unlike other heterogeneous materials, snow exhibits strong rate-dependent behavior, which significantly influences also its failure behavior and hence snow strength. The AE response is expected to reveal how damage at the microscale $\left(\sim 1 \mathrm{~cm}^{2}\right)$ develops at different loading rates before complete sample failure.

Given the lack of understanding of how failures in WLS develop, our study aims at monitoring the AE response during snow failure experiments using samples that are large enough to allow for spatial interaction of local failures. We therefore perform load-controlled experiments with large layered snow samples for different loading rates and record the $\mathrm{AE}$ generated by the failure process. We use the theory of critical phenomena to analyze the AE response and identify precursory features. In particular, we study the influence of the loading rate on the $A E$ signatures and discuss the implications for understanding the damage process leading to snow failure.

\section{METHODS}

\subsection{Loading apparatus}

We developed a new apparatus for fully load-controlled experiments, which allows varying the loading rate and loading angle. The sample size should allow for detecting 


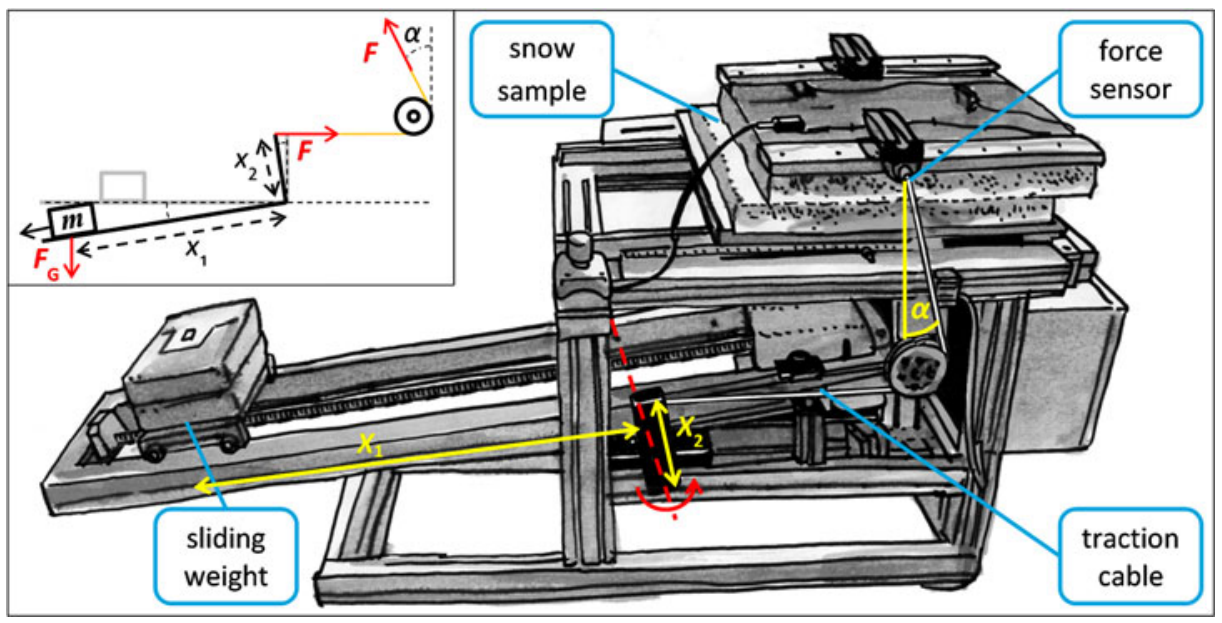

Fig. 1. Schematic representation of the loading apparatus including a snow sample after fracture. The sample failed in the weak layer in the middle. The angle $\alpha$ to the sample simulates the slope angle and can be altered shifting the sample horizontally on the apparatus. The sliding weight exerts the force on the snow sample via the tilting mechanism (red line shows tilting axis) and the traction cable to the metal plate on top of the sample. A motor moves the weight increasing the distance $x_{1}$, and hence the load exerted on the sample increases with $F \sim x_{1} / x_{2}$. The inset shows a schematic representation of the tilting mechanism with the exerted force.

progressive damage, i.e. failure organization at the microscale, which does not yet lead to complete failure. A schematic representation of the apparatus is shown in Figure 1. The quadratic snow samples had a side length of $50 \mathrm{~cm}$ and a height of $10-20 \mathrm{~cm}$. The samples were placed between two rigid metal plates on the top and the bottom parallel to the WL (Fig. 2). The loading force was exerted by the gravitational force of a weight $(m=25-75 \mathrm{~kg})$, which was positioned on a tilting mechanism connected to the top plate by a cable on each side. As the experiment started, the weight was moved horizontally with constant speed by an electrical motor increasing the distance $x_{1}$ to the tilting axis, whereas the distance $x_{2}$ between the fixation of the cables and the tilting axis was constant. Thus, the loading force exerted on the sample increased linearly with $F=m g x_{1} / x_{2}$. The loading rate could be varied between 4 $\mathrm{Pa} \mathrm{s}^{-1}$ and $800 \mathrm{~Pa} \mathrm{~s}^{-1}$ by modifying the speed of the weight. The load was measured by two force sensors (U9C HBM) at the connection between the top plate and the cables; the maximal possible load was $20 \mathrm{kPa}$. The loading angle $\alpha$ (angle between top plate and cables) could be varied by changing the horizontal position of the sample on the apparatus. Loading angles between $0^{\circ}$ and $45^{\circ}$ were possible. The position of the cable fixation to the top plate

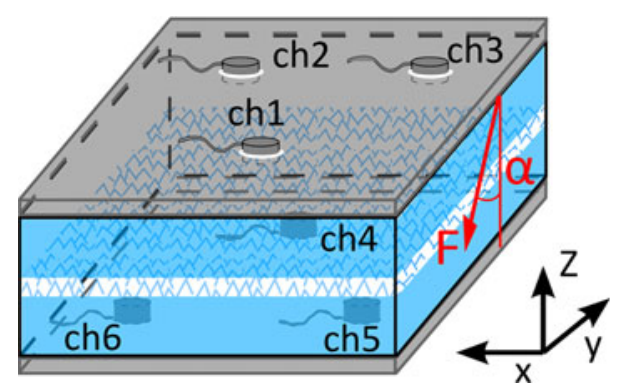

Fig. 2. Schematic representation of a snow sample with the metal plates and the six acoustic sensors (ch1 to ch6). The weak layer plane is parallel to the metal plates. The loading force is applied on the top plate with angle $\alpha$ from the vertical. depended on the loading angle and was adjusted to avoid torque in the WL plane.

\subsection{Particle image velocimetry analysis}

The displacement field at the side of the samples was determined employing the particle image velocimetry (PIV) technique, which has been previously used to compute the displacement field in snow experiments (e.g. Reiweger and others, 2010; van Herwijnen, 2013). The displacement field was obtained from a video sequence with $30 \mathrm{fps}$ and $1920 \times 1080$ pixels resolution $\left(3.6\right.$ pixels $\mathrm{mm}^{-1}$ ) with the Fluere 0.9 PIV software (Lynch and Scarano, 2014) comparing the first frame of the video sequence and the consecutive frames. The contrast of the images was enhanced by creating a pattern of dots on the samples. We used a calibration image and second-order image mapping, to correct image misalignment and distortion and convert the displacement field from pixel to millimeter. Vibrations and wobbling of the testing apparatus caused noise in the displacement field, which were corrected by subtracting the displacement of the base plate from the displacement field. A window size of $24 \times$ 24 pixels and a window spacing of four pixels were used for the PIV computation resulting in $450 \times 90$ measuring points across the sample. The strain in the WL was computed from the difference between the average displacement of two 40-pixels high stripes above and below the WL.

\subsection{Recording of the $\mathrm{AE}$}

The $\mathrm{AE}$ generated during the loading experiments were recorded by six piezoelectric sensors. Three sensors were placed on top of the sample and three sensors at the bottom of the sample (Fig. 2). The sensor arrangement was chosen to allow for AE localization (not presented here). The sensors were inserted into holes going through the metal plates and were frozen to the snow to ensure proper acoustic coupling. We used six wideband piezoelectric acoustic sensors (Mistras WD, 20-1000 kHz). The sampling rate was $1 \mathrm{MHz}$. The $\mathrm{AE}$ were recorded with a system by Physical Acoustics ( $\mathrm{PCl} 2 \mathrm{~A} / \mathrm{D}$ cards), which allowed for 


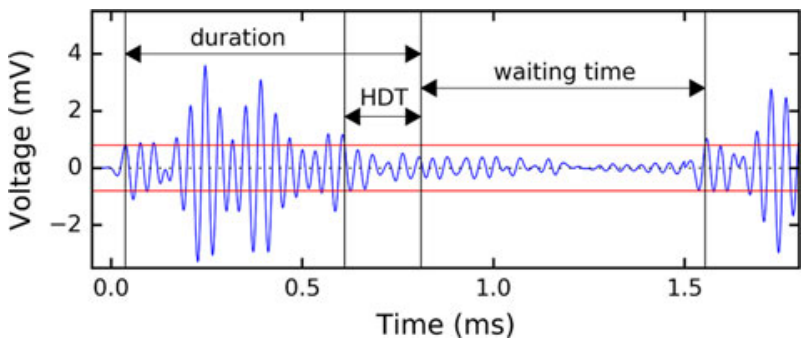

Fig. 3. Exemplary AE signal to illustrate hit detection and feature extraction. The hit starts as the signal exceeds the threshold (red line) and ends when the signal is lower than the threshold for a time longer than the hit definition time (HDT). The waiting time is the distance between two consecutive hits.

real-time waveform acquisition and feature extraction on six channels. A more detailed description of the recording system is found in Reiweger and others (2015b).

The signals of the acoustic sensors were continuously monitored. Every time a signal exceeded a fixed threshold, a hit with several $\mathrm{AE}$ features and the belonging waveform was recorded (Fig. 3). Signal recording ended as soon as the signal did no longer exceed the threshold for a given time. The energy of the hit (given in atto $\left(10^{-18}\right)$ Joule: aJ) is the integral of the squared signal amplitude (voltage) over the hit duration divided by a reference resistance $(10 \mathrm{k} \Omega)$. The waiting time is the time between the end of a hit and the next hit. For a more detailed description and the definition of the AE parameters, the reader is referred to Grosse and Ohtsu (2008).

Before each experiment, we assessed the acoustic wave attenuation in the snow sample and the losses at the snowsensor interface with a pencil lead fracture test. This procedure allowed adjusting the signal amplification (20,40 or $60 \mathrm{~dB}$ ) and the threshold for each experiment so that they were in the right range. The settings were the same for all channels for a given experiment. Approximate selection in the right range is sufficient since the features we analyzed are robust with respect to changes in the absolute value of the $\mathrm{AE}$ signal amplitude. In particular, the $b$-value, the relative temporal change of the energy rate and the waiting time do not depend on the absolute value of the AE energy.

\subsection{Analysis of AE data}

The energy of the $A E$ hits is usually distributed according to a power-law relation (Eqn (1)), and the exponent is referred as the $b$-value. To compute the $b$-value, we used the python package Powerlaw (Alstott and others, 2014) that employs the method described by Clauset and others (2009). It allows for a robust fit of power-laws to experimental data. The goodness-of-fit of the $b$-values was tested comparing the hypothesized power-law distribution with an exponential distribution (Alstott and others, 2014). The energy rate was computed with a running time window dividing the sum of the energy by the length of the window. The inverse waiting time was obtained by inverting the mean waiting time, which was as well computed with a running window. The window with time $t_{i}$ included the data points $\left(y_{i-n}, \cdots\right.$, $\left.y_{i-1}, y_{i}\right)$, in order to include in the computation just information prior to the time point $t_{i}$. We used running windows with variable size of $n$ hits for the time evolution of the $b$-value $(n=250)$, the inverse waiting time $(n=100$ or 300$)$ and the energy rate $(n=100$ or 300$)$. For the energy and the waiting time, the separation between two consecutive windows was one hit, whereas for the $b$-value, it was 20 hits unless otherwise specified. The data of the different channels were always treated separately.

To allow for direct comparison of the energy rate for different loading rates $\dot{\sigma}=\mathrm{d} \sigma / \mathrm{d} t$, the temporal energy rate $\mathrm{d} E / \mathrm{d} t$ can be transformed into an energy rate of change with stress $\mathrm{d} E / \mathrm{d} \sigma=(\mathrm{d} E / \mathrm{d} t)(\mathrm{d} t / \mathrm{d} \sigma)$ substituting the time $t$ with the stress $\sigma$, since the stress increased linearly with time. If an exponential dependence of the temporal energy rate $\mathrm{d} E / \mathrm{d} t \sim \mathrm{e}^{-\gamma_{t}\left(t_{\text {tailure }}-t\right)}$ is assumed, the energy rate of change with stress will be also exponential with:

$$
\frac{\mathrm{d} E}{\mathrm{~d} \sigma}=\frac{\mathrm{d} E}{\mathrm{~d} t} \frac{\mathrm{d} t}{\mathrm{~d} \sigma} \sim \mathrm{e}^{\gamma_{\mathrm{t}}} \frac{1}{\dot{\sigma}} \sim \mathrm{e}^{\gamma_{\mathrm{t}} \sigma / \dot{\sigma}} \sim \mathrm{e}^{\gamma_{\sigma} \sigma},
$$

with the relation $\gamma_{\mathrm{t}}=\gamma_{\sigma} \dot{\sigma}$. In the following, we will refer to the energy rate as the energy rate of change with stress $\mathrm{d} E / \mathrm{d} \sigma$, if not specified otherwise.

\subsection{Breeding of synthetic WLs}

We produced snow samples including an artificially grown WL of depth hoar crystals following the method described by Fukuzawa and Narita (1993). A snow sample was prepared with an area of $50 \mathrm{~cm} \times 120 \mathrm{~cm}$ and height of 12 $15 \mathrm{~cm}$ consisting of three layers of different density (Fig. 4). The $5 \mathrm{~cm}$ thick base layer was produced by sieving natural snow (rounded grains) through a fine mesh $(2 \mathrm{~mm})$ directly onto the bottom metal plate used for the shear apparatus. The middle layer, the subsequent $\mathrm{WL}$, was produced by sieving machine-made nature-identical new snow (Schleef and others, 2014) through a coarser mesh $(8 \mathrm{~mm})$ onto the bottom layer. The thickness of this layer was $\sim 15 \mathrm{~mm}$. The top layer, $\sim 6 \mathrm{~cm}$ in thickness, was produced separately using the same method as for the base layer. After 2-3 d of sintering $\left(\right.$ at $\left.-20^{\circ} \mathrm{C}\right)$, the top layer was placed on the lowdensity middle layer. Then, the layered sample was subjected to a temperature gradient of $1-1.5 \mathrm{~K} \mathrm{~cm}^{-1}$ for $7 \mathrm{~d}$ inducing snow metamorphism. As a result, the snow of the less dense middle layer was transformed to depth hoar. The depth hoar structure is anisotropic, coarse and loosely bonded, and therefore particularly fragile under shear loading (Reiweger and Schweizer, 2013). The snow of the base and top layer was transformed as well, but due to its higher density, the metamorphism was less pronounced. From every breading sample, we obtained two samples for the loading experiments with a quadratic area of $50 \mathrm{~cm} \times$ $50 \mathrm{~cm}$ each. The remaining section in the middle was used

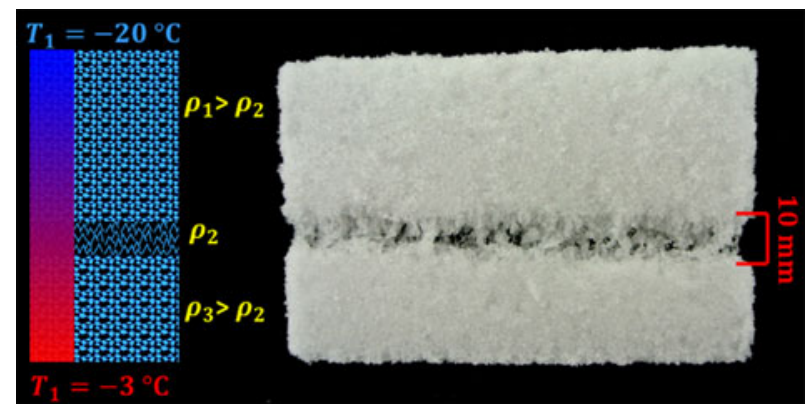

Fig. 4. Layered sample including a weak layer: schematically (left), thin section (right). The coarse depth hoar weak layer in the middle is well visible. 
Table 1. Snow properties of top layer (slab), weak layer and bottom layer (base). We report the mean and the range, except for hand hardness index we provide the median, and for grain shape the most frequent shape.

\begin{tabular}{|c|c|c|c|c|c|c|c|c|}
\hline \multirow[b]{2}{*}{ Sample } & \multirow[b]{2}{*}{$\begin{array}{l}\text { Thickness } \\
(\mathrm{mm})\end{array}$} & \multicolumn{4}{|c|}{ Classical characterization (ICSSG) } & \multicolumn{2}{|l|}{$\mathrm{CT}$} & \multirow{2}{*}{$\begin{array}{l}\text { SMP } \\
\text { Penetration force } \\
(N)\end{array}$} \\
\hline & & Grain shape & $\begin{array}{l}\text { Grain size } \\
(\mathrm{mm})\end{array}$ & $\begin{array}{l}\text { Hand hardness } \\
\text { index }\end{array}$ & $\begin{array}{l}\text { Density } \\
\left(\mathrm{kg} \mathrm{m}^{-3}\right)\end{array}$ & $\begin{array}{l}\text { CT-derived density } \\
\left(\mathrm{kg} \mathrm{m}^{-3}\right)\end{array}$ & $\begin{array}{l}\text { SSA } \\
\left(\mathrm{m}^{2} \mathrm{~kg}^{-1}\right)\end{array}$ & \\
\hline Slab & 50 & $\mathrm{FC},(\mathrm{RG}$ or $\mathrm{DH})$ & $1.2,0.75-1.75$ & $4,2-(4-5)$ & $334,212-410$ & $332,202-427$ & $16.6,15.0-18.9$ & $8,0.2-21$ \\
\hline WL & $10 \pm 3$ & $\mathrm{DH}$ & $2.9,2.25-3.5$ & $2,1-2$ & - & $167,139-198$ & $17.5,14.3-20$ & $0.7,0.08-1.73$ \\
\hline Base & 50 & $\mathrm{FC},(\mathrm{RG}$ or $\mathrm{DH})$ & $1.2,0.75-1.75$ & $4,2-(4-5)$ & $339,219-429$ & $318,200-396$ & $16.7,15.0-18.4$ & $9,0.6-18$ \\
\hline
\end{tabular}

for the snow characterization (Table 1). Grain size, grain type, hand hardness index and density were characterized as described in Fierz and others (2009). Three snow micropenetrometer resistance profiles were recorded (Schneebeli and Johnson, 1998) for each sample. In addition, we characterized the microstructure by $\mathrm{x}$-ray computer tomography (Schneebeli and Sokratov, 2004). For each layer, a section with a volume of $15 \mathrm{~mm} \times 15 \mathrm{~mm} \times 4.5 \mathrm{~mm}$ was scanned and used to derive the snow properties.

\section{RESULTS}

We performed loading experiments with different loading rates $\left(400,168\right.$ and $\left.32 \mathrm{~Pa} \mathrm{~s}^{-1}\right)$. In the first section of the results, we describe our findings on the mechanical deformation. In the second section, we present the typical AE features observed before failure. Finally, we report the influence of the loading rate on the $\mathrm{AE}$ response and discuss some cases of samples that did not fail.

Table 2 shows a summary of the loading experiments. Most samples loaded at the lowest loading rate $\left(32 \mathrm{~Pa} \mathrm{~s}^{-1}\right.$ ) did not fail. Only sample LDL04B failed during the second loading cycle. The first loading cycle was stopped at 13.8 $\mathrm{kPa}$ without reaching the failure point. The loading experiments were performed with different loading angles $(\alpha=$ $0^{\circ}, 15^{\circ}$ and $\left.35^{\circ}\right)$. We did not observe any significant dependence of the $\mathrm{AE}$ signature on the loading angle. Therefore, we do not take into account the loading angle in the following analysis.

The applied load induced a progressive deformation of the samples. An exemplary displacement field obtained with PIV is shown in Figure 5. The deformation was concentrated in the zone between 60 and $50 \mathrm{~mm}$ height corresponding to the WL where the failure eventually occurred. A concentration of the deformation in the WL was observed for all samples. At failure, a crack was formed along the WL, and consequently led to the collapse of the WL. The propagation of the crack could not be observed. In Figure 6 a, we exemplarily compare the stress-strain relations of three experiments (samples LDL07A, LDL12B and LDL04B) with different loading rates at the same loading angle $\alpha=35^{\circ}$. For the experiments with the high loading rates (168 and $400 \mathrm{~Pa} \mathrm{~s}^{-1}$ ), we observed brittle fracture with very low strain prior to failure. For the slowest experiment $\left(32 \mathrm{~Pa} \mathrm{~s}^{-1}\right)$, we observed much larger strain, and at $13.8 \mathrm{kPa}$, the experiment was stopped without reaching complete failure. Figure $6 \mathrm{~b}$ shows the strain rate as a function of increasing stress. We used a Kalman filter (Kalman, 1960) to extract the strain rate from the noisy strain data. The strain rate considerably varied. To show the general trend, we fitted a linear function to the strain data (Fig. 6b, dotted line). The strain rate increased with increasing load for all loading rates and reached $\sim 2 \times$ $10^{-4} \mathrm{~s}^{-1}$ for a loading rate of $400 \mathrm{~Pa} \mathrm{~s}^{-1}$ and $0.9 \times 10^{-5} \mathrm{~s}^{-1}$ for $168 \mathrm{~Pa} \mathrm{~s}^{-1}$ (strength 8.1 and $8.3 \mathrm{kPa}$, respectively). For the slow loading rate of $32 \mathrm{~Pa} \mathrm{~s}^{-1}$, the strain rate reached $\sim 4.5 \times 10^{-4} \mathrm{~s}^{-1}$.

\subsection{AE signatures before failure}

We will describe the failure process and the typically observed AE signatures using the sample LDL07A ( $\alpha=35^{\circ}$, stress rate $=400 \mathrm{~Pa} \mathrm{~s}^{-1}$ ) as an illustrative example, in particular focusing on the features in the AE signal characteristic for the time preceding complete failure of the sample.

\subsubsection{Energy distribution and b-value}

The probability density of the energy $E$ of the recorded $A E$ for the sample LDL07A and its evolution in time were analyzed (Fig. 7). The goodness-of-fit of the power-law distribution was tested by comparing it to an exponential distribution. The power-law fit was better than the exponential fit regardless whether all events up to fracture or only events in a given time window were considered. However, the corresponding complementary cumulative distributions exhibited a significant curvature (Fig. 7b). The $b$-value for all the events up to fracture was $1.55 \pm 0.2$ (channel 2). Figure 7 shows (a) the evolution of the $b$-value toward failure computed using a running window of $n=250$ hits and a minimum value for the fit of $600 \mathrm{aJ}$, and (b) the complementary cumulative

Table 2. Summary of the test conditions and results for the 18 samples used for this study

\begin{tabular}{llllr}
\hline Sample & $\begin{array}{l}\text { Loading angle } \alpha \\
\left({ }^{\circ}\right)\end{array}$ & $\begin{array}{l}\text { Loading rate } \\
\left(\mathrm{Pa} \mathrm{s}^{-1}\right)\end{array}$ & Failure & $\begin{array}{l}\text { Strength } \\
(\mathrm{kPa})\end{array}$ \\
\hline LDL03A & 15 & 164 & Yes & 12.9 \\
LDL03B & 15 & 32 & No & $>7.6$ \\
LDL04A & 0 & 32 & No & $>14.1$ \\
LDL04B_load01 & 35 & 32 & No & $>13.8$ \\
LDL04B_load02 & 35 & 32 & Yes & 15.7 \\
LDL05A & 35 & 168 & Yes & 11.8 \\
LDL05B & 0 & 168 & Yes & 10.5 \\
LDL06A & 15 & 32 & No & $>20$ \\
LDL06B & 35 & 400 & Yes & 8.6 \\
LDL07A & 35 & 400 & Yes & 8.1 \\
LDL07B & 15 & 168 & No & $>20$ \\
LDL09A & 0 & 168 & Yes & 8.7 \\
LDL09B & 0 & 32 & No & $>20$ \\
LDL10A & 35 & 168 & Yes & 3 \\
LDL10B & 15 & 168 & Yes & 3.2 \\
LDL11A & 15 & 400 & Yes & 13.2 \\
LDL11B & 0 & 400 & Yes & 11.6 \\
LDL12A & 0 & 400 & Yes & 5.4 \\
LDL12B & 35 & 168 & Yes & 8.3 \\
\hline
\end{tabular}



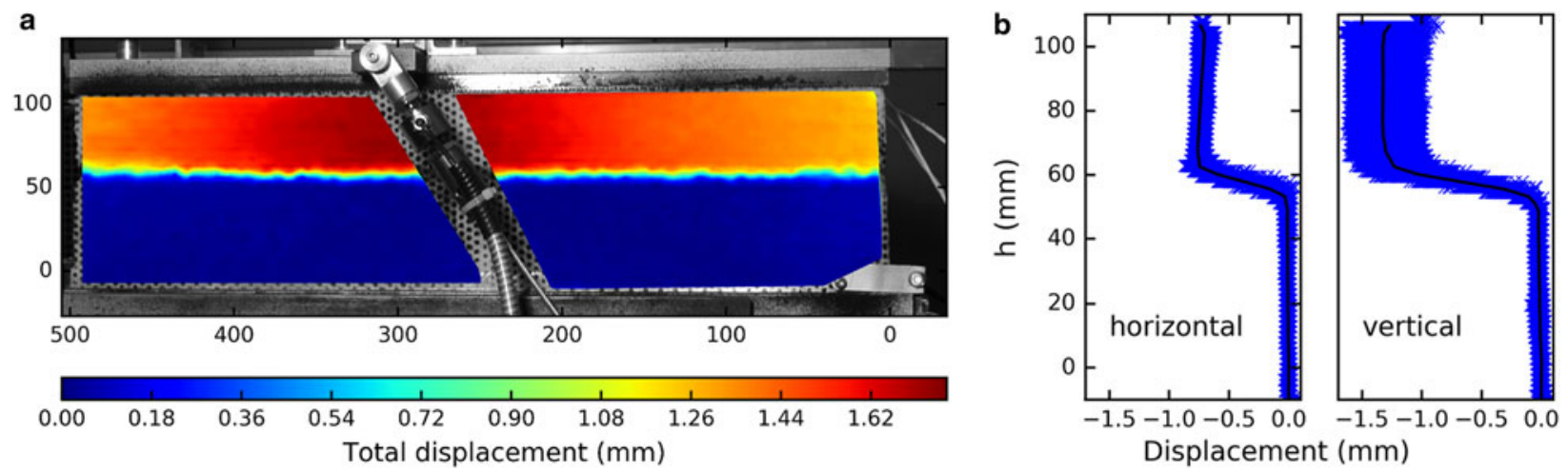

Fig. 5. (a) Two-dimensional map of the total displacement relative to the bottom plate immediately before failure. The $x$ - and $y$-axis show the dimension of the sample in $\mathrm{mm}$. (b) Vertical and horizontal displacement at different heights. The scatterplot in blue shows the values for each evaluated point. The black lines indicate the mean at each height $h$. Sample LDL04B with loading angle $\alpha=35^{\circ}$.

distribution of event energy for eight different running windows with the corresponding power-law fits for channel 2 . The initial $b$-value for channel 2 was $\sim 2.5$ and decreased continuously to 1.4 at failure. The decrease of the $b$-value was observed for each channel with similar initial and final $b$-values for all channels except for channel 1 , which had a poor sensitivity and recorded only few hits during the last $2.5 \mathrm{~s}$ of the experiment.

\subsubsection{Energy rate}

The AE energy rate is an indicator of the amount of new damage created in the sample, since elastic energy is
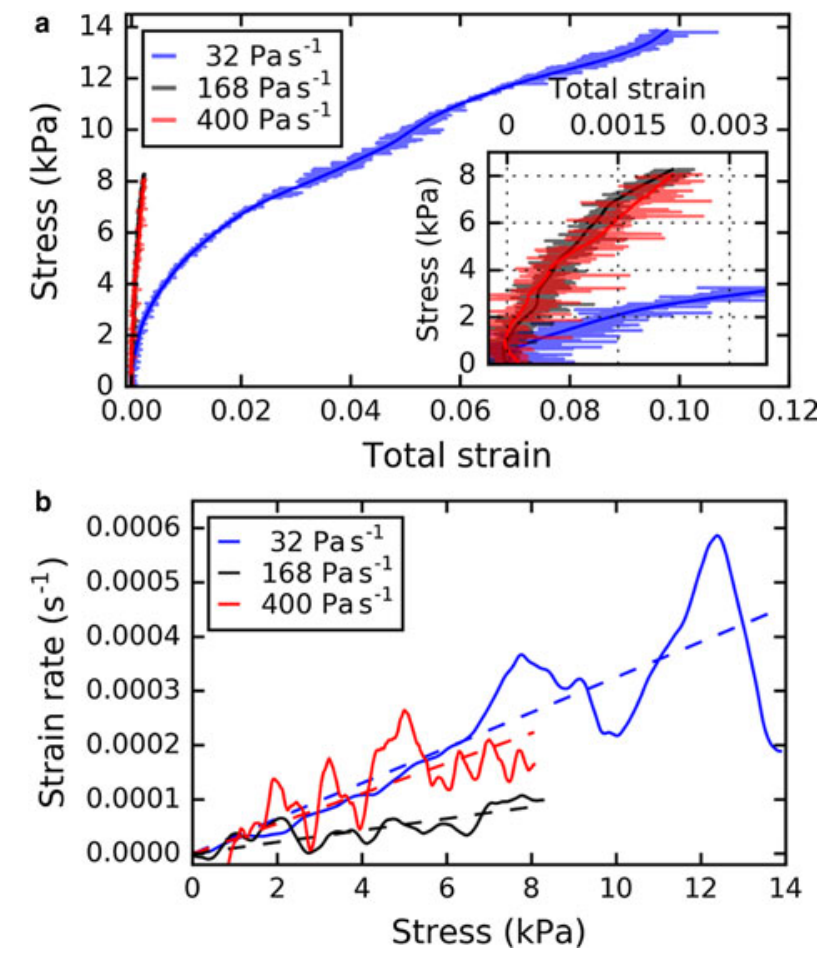

Fig. 6. (a) Stress-strain relation of weak layer for three experiments with different loading rates. The inset shows the stress for very low strain (below 0.0035). (b) Strain rate vs stress for the same three experiments. The solids lines in (a) and (b) were obtained from the noisy data with a Kalman filter; the dashed line in (b) is a linear fit of the strain rate. The loading angle was $\alpha=35^{\circ}$ for all three samples (LDL04B_load01, LDL12B and LDL07A). released in the form of acoustic waves whenever a microcrack forms or grows. The energy rate before failure for sample LDL07A computed with a moving window $n=100$ hits is shown in Figure 8. The AE energy rate increased exponentially toward failure. The coefficient $\gamma_{\sigma}$ was computed with a linear regression of the logarithmic scaled energy rate (red line in Fig. 8). The energy rate at failure varied by almost two orders of magnitude between the different channels, since the magnitude of the measured AE signal depends on sensor-snow coupling and attenuation within snow. However, the increase is expected to be independent of the absolute value of the AE signal. Nonetheless, we observed some variation between channels of the
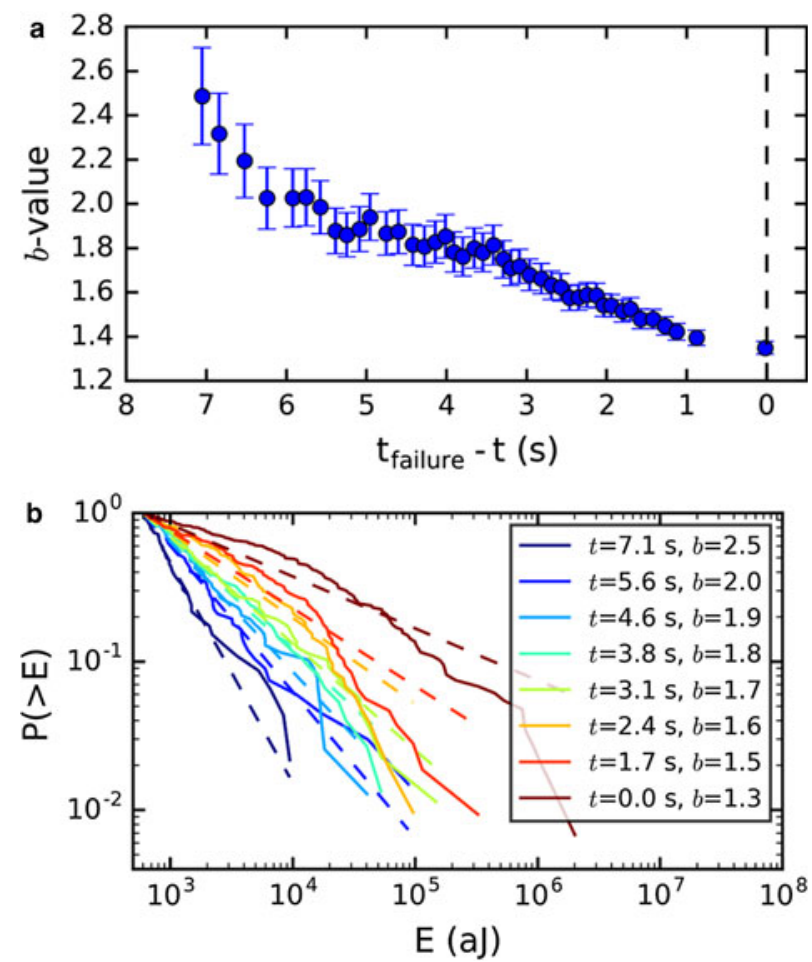

Fig. 7. (a) Evolution of $b$-value toward failure for sample LDL07A, ch2. Running window size $n=250$ hits. The error bars indicate the std dev. (b) Complementary cumulative distribution of energy $E$ for eight different windows with corresponding power-law fits (dashed lines). The time $t$ in the legend indicates the time before complete failure. 
exponential coefficient $\gamma_{\sigma}$ and the range at which the energy rate increased exponentially. The mean value of all six channels was $\gamma_{\sigma}=1.4 \pm 0.5 \times 10^{-3} \mathrm{~Pa}^{-1}$. The many orders of magnitudes higher energy rate recorded at and after failure was produced by the collapse of the $\mathrm{WL}$ and by friction during the sliding or the upper slab after failure.

\subsubsection{Inverse waiting time}

The waiting time is defined as the time between the end of an $\mathrm{AE}$ hit and the start of the next, and therefore, the inverse waiting time is the hit mean frequency or frequency of the $\mathrm{AE}$ activity. The time evolution of the inverse mean waiting time for the sample LDL07A channel 2 is shown in Figure $8 \mathrm{~b}$. We observed an exponential increase of the inverse waiting time toward failure. The exponential increase was observed for all channels, but had different magnitudes. The increase of the inverse waiting time indicated an acceleration of the damage frequency, since the time between two hits decreased.

\subsection{Loading rate dependence of AE signatures}

Given that the deformation and failure behavior depends on loading rate (see above), we expected also the $\mathrm{AE}$ response to depend on loading rate. We computed the time evolution of the $b$-value for samples, which were loaded with three different loading rates $\left(32,168\right.$ and $\left.400 \mathrm{~Pa} \mathrm{~s}^{-1}\right)$. Figure 9 shows examples of the evolution of the $b$-value for each loading rate (samples: LDL07A, LDL12B and LDL04B_load02). For all three rates, the power-law distribution provided the better fit for all windows. For the low loading rates, the
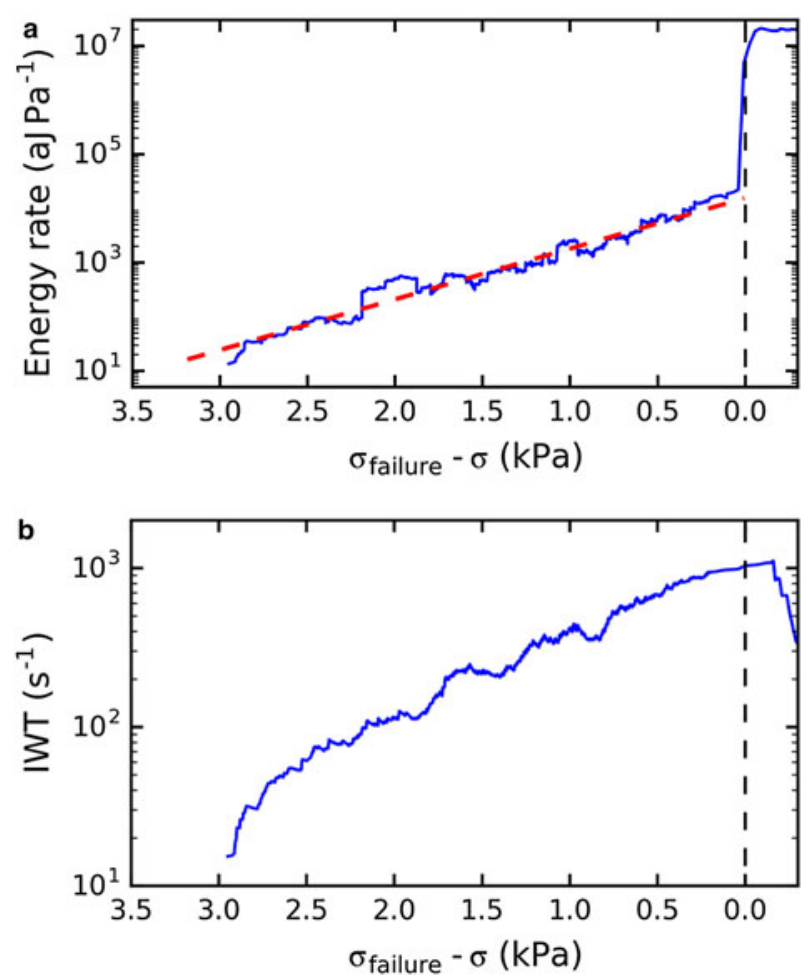

Fig. 8. (a) Energy rate evolution with increasing load for sample LDL07A (ch2; $n=100$ hits). The red dashed line represents a linear fit of the logarithmically scaled energy rate, which increased exponentially before failure. (b) Evolution with increasing load of the inverse mean waiting time (IWT) for sample LDL07A (ch2) with running window size $n=100$ hits. decrease of the $b$-value was less pronounced. The $b$-value for the only sample with the lowest loading rate which failed (LDL04B_load02) was almost constant considering the entire loading period and the $b$-value at failure was higher. However, a modest decrease of the $b$-value was observed shortly before failure (Fig. 9). To allow for comparison of the results, we performed a linear regression with $b=a$ $\left(t_{\text {failure }}-t / t_{\text {failure }}\right)+c$ (dashed line in Fig. 9). We performed the fit on $b$-value evolution of several experiments with different loading rates (five samples and 19 channels for 400 $\mathrm{Pa} \mathrm{s}^{-1}$, and four samples and 18 channels for $168 \mathrm{~Pa} \mathrm{~s}^{-1}$ ). The channels and samples for which too few AE hits $(<800)$ were available were not considered for the evaluation. The results of the fits are summarized as boxplots in Figure 10. The median value of the slope a was lower for the lower loading rate $\left(a=1.4\right.$ for $400 \mathrm{~Pa} \mathrm{~s}^{-1}$ and $\mathrm{a}=0.5$ for $168 \mathrm{~Pa} \mathrm{~s}^{-1}$ ), whereas the value of the fitting line at $t=$ $t_{\text {failure }}$ was higher for the slower loading rate $(c=1.3$ for $400 \mathrm{~Pa} \mathrm{~s}^{-1}$ and $c=1.6$ for $168 \mathrm{~Pa} \mathrm{~s}^{-1}$ ). The mean coefficient of determination $R^{2}$ was 0.45 for $400 \mathrm{~Pa} \mathrm{~s}^{-1}$ and 0.25 for $168 \mathrm{~Pa} \mathrm{~s}^{-1}$. The $P$-value was below 0.002 for all linear regressions. For some samples, the slope was almost zero or even negative. However, we observed a decrease of the $b$-value shortly before failure at least in one channel for every sample.

The absolute value of the energy rate per unit time $\mathrm{d} E / \mathrm{d} t$ was higher for the experiments at higher loading rates. This finding is not surprising since with a faster increase of the load, a higher damage rate and consequently a higher $\mathrm{AE}$ energy rate is expected. To allow for direct comparison, we used the energy rate per unit stress $\mathrm{d} E / \mathrm{d} \sigma$. Figure 11 shows an example of the temporal evolution of the energy rate $\mathrm{d} E / \mathrm{d} \sigma$ for the three loading rates. The energy rate increased exponentially before complete failure for all loading rates. However, the range over which the exponential growth was observed varied substantially between the samples and channels. The exponential coefficient $\gamma_{\sigma}$ and the energy rate at failure were obtained with a linear regression of the logarithm of the energy rate for several samples. The channels and samples for which too few AE hits $(<800)$ were available were not considered for the evaluation. The time range for the fit was chosen manually for each channel. Figure 12 shows the exponential coefficient $\gamma_{\sigma}$ and the energy rate at failure for the experiments with the two loading rates 400 and $168 \mathrm{~Pa} \mathrm{~s}^{-1}$. The mean value of $\gamma_{\sigma}$

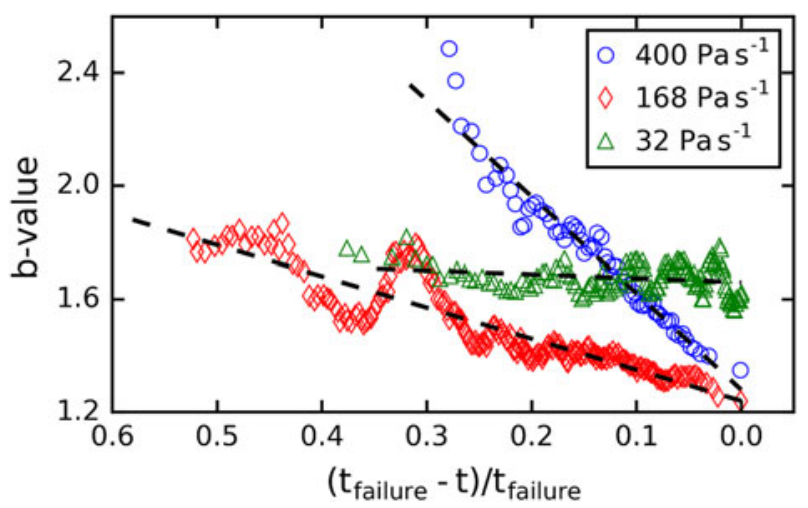

Fig. 9. Evolution of $b$-value before complete failure for different loading rates $\left(400,168\right.$ and $\left.32 \mathrm{~Pa} \mathrm{~s}^{-1}\right)$. The dashed lines represent a linear regression. Samples shown: LDL07A, LDL12B and LDL04B_load02, window size $n=250$. 

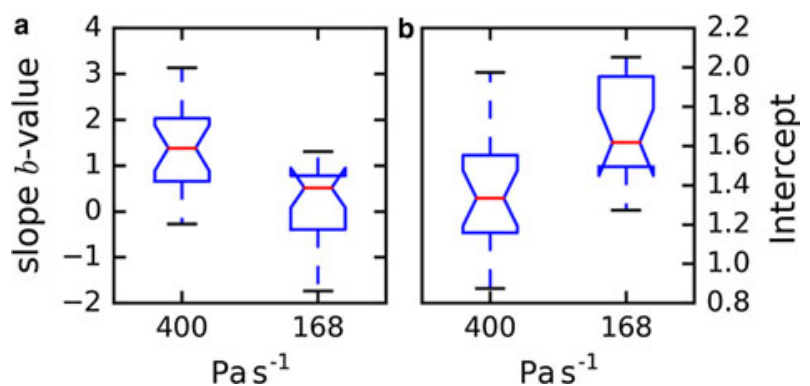

Fig. 10. Boxplots summarizing the linear regression to the $b$-value time evolution of several samples for two different loading rates (168 $\mathrm{Pa} \mathrm{s}^{-1}, N=18 ; 400 \mathrm{~Pa} \mathrm{~s}^{-1}, N=19$ ). (a) The slope of the $b$-value evolution with time. (b) $b$-value at failure obtained from the intercept of the linear fit at the failure point.

was almost the same for both loading rates $\left(1 \times 10^{-3} \mathrm{~Pa}^{-1}\right.$ for $400 \mathrm{~Pa} \mathrm{~s}^{-1}$ and $0.9 \times 10^{-3} \mathrm{~Pa}^{-1}$ for $168 \mathrm{~Pa} \mathrm{~s}^{-1}$ ). The mean exponential coefficient for the single slow experiment that completely fractured was $\gamma_{\sigma}=0.35 \times 10^{-3} \mathrm{~Pa}^{-1}$ (LDL04B_load02, mean over five channels). This value was one-third of the value observed for the samples with brittle fracture. The energy rate at failure was similar at the two faster loading rates (Fig. 12b) and for the single slow experiment that failed $\left(\mathrm{dE} / \mathrm{d} \sigma\left(\sigma_{\text {failure }}\right)=10^{4.7 \pm 0.5}\right.$ al $\left.\mathrm{Pa}^{-1}\right)$. However, the absolute value of the energy rate cannot easily be compared since the measured energy values depend strongly on the sensor-snow coupling and attenuation within snow ( $1 \mathrm{~dB} \mathrm{~cm}^{-1}$; Capelli and others, 2016) and the absolute values varied considerably (Fig. 12b).

The magnitude of the inverse waiting time was much lower for the slower experiments, whereas the evolution before failure was similar for all three loading rates (Fig. 13). The waiting time increased exponentially before failure for all three loading rates.

\subsection{AE signatures in the absence of complete failure}

In the following, we present two examples of loading experiments without complete failure of the sample and analyze the observed AE features. Sample LDL04B was loaded with $32 \mathrm{~Pa} \mathrm{~s}^{-1}$ up to $13.8 \mathrm{kPa}$ without fracturing. Figure 14 shows the time evolution of $b$-value, inverse waiting time and energy rate. For all windows, the power-law distribution provided the better fit, and the $b$-value did not change much

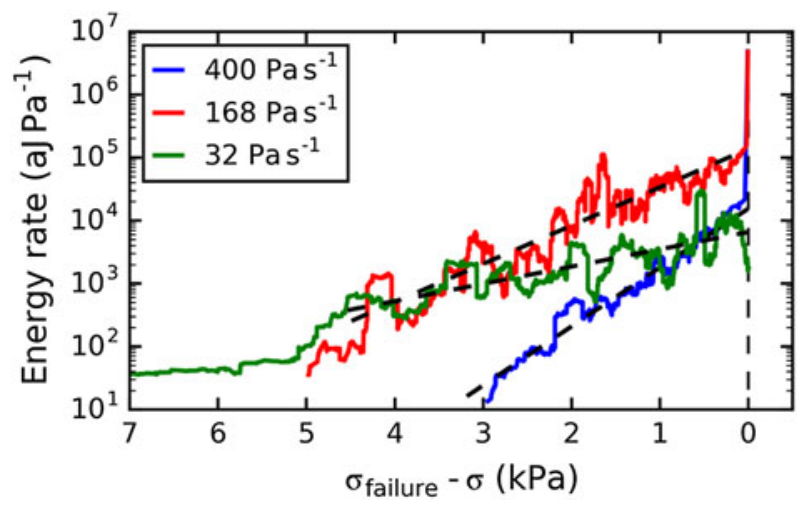

Fig. 11. Evolution of the energy rate with increasing load for three different loading rates. Samples shown: LDL07A, LDL12B and LDL04B_load02, window size $n=100$.

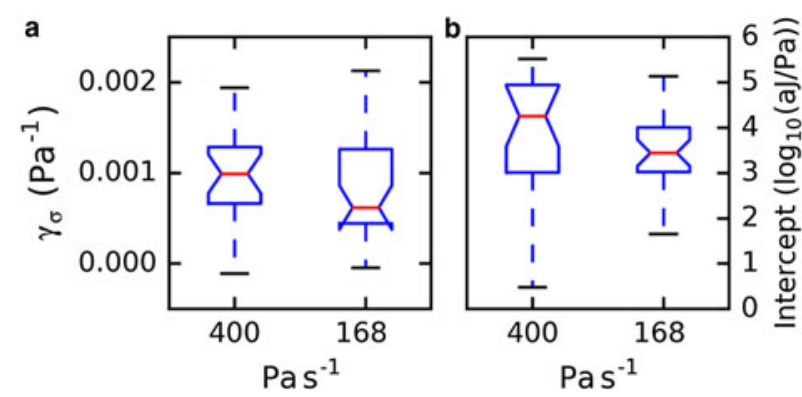

Fig. 12. Boxplots summarizing the temporal evolution of the energy rate for several samples and for two different loading rates (168 $\mathrm{Pa} \mathrm{s}^{-1}$, $N=18 ; 400 \mathrm{~Pa} \mathrm{~s}^{-1}, N=19$ ). (a) Exponential coefficient $\gamma_{\sigma}$. (b) Energy rate at failure (logarithmic scale) obtained from the intercept of the linear fit at the failure point.

over the entire duration of the experiment but varied. Similarly, the inverse waiting time and the energy rate did not increase exponentially as observed for the samples that failed, but varied with increasing amplitude in time. The constant $b$-value as well as the lack of exponential increase of energy rate and inverse waiting time suggest that the damage process was stable, i.e. did not change over the entire duration of loading. However, the variations indicate that the damage process was not continuous but consisted of a series of bursts, the size of the bursts increasing with increasing load.

The second example of a loading experiment without complete failure is sample LDL07B, which was loaded at a rate of $168 \mathrm{~Pa} \mathrm{~s}^{-1}$. In addition to the previously described decrease of $b$-value and increase of energy rate and waiting time over the entire duration of the experiment, we observed a spike in the inverse waiting time, and energy rate with a simultaneous rapid decrease of the $b$-value at $28.2 \mathrm{~s}$ before reaching the maximum load (Fig. 15, dotted red line). All parameters indicated an acceleration of the damage process over a short time without observing fracture of the whole sample. Moreover, the magnitude of the observed change in the AE features varied strongly from channel to channel. It was pronounced for ch1, ch2 and ch5, whereas for the other channels (ch3, ch4 and ch6) was barely visible. We assume that the acceleration of the AE activity was caused by a major local failure that did not spread through the entire sample (partial failure). The AE response was, therefore, not equally present in the overall signal of the different channels,

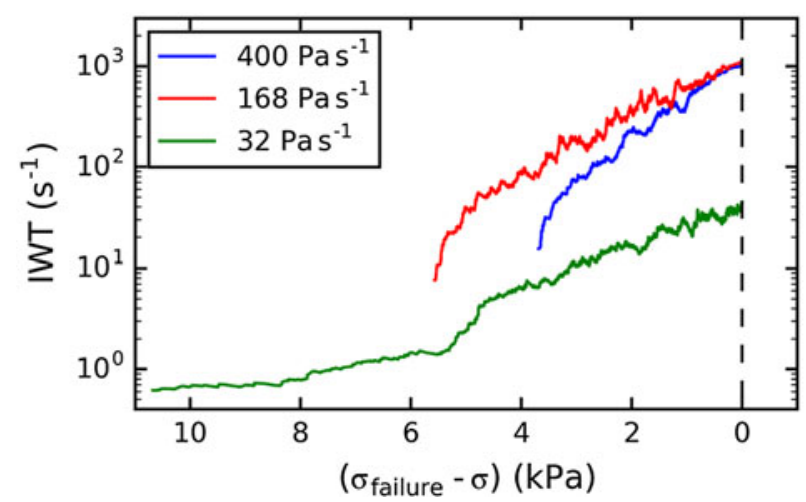

Fig. 13. Evolution of the inverse waiting time with increasing load for different loading rates. Samples shown: LDL07A, LDL12B and LDL04B_load02, window size $n=100$. 

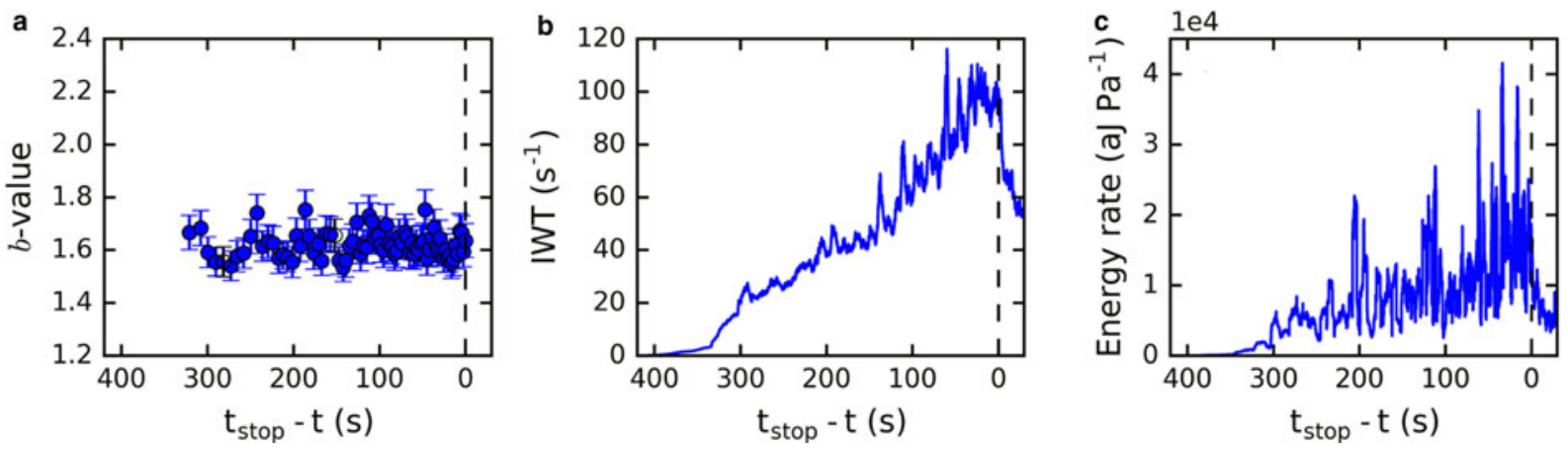

Fig. 14. AE features for the sample LDL04B (ch2), which was loaded with $32 \mathrm{~Pa} \mathrm{~s}^{-1}$ and did not fracture. Evolution with time for (a) $b$-value (running window size $n=300$ hits, window separation 200 hits), (b) inverse waiting time (IWT) ( $n=300$ hits), (c) energy rate ( $n=200$ hits). The error bars indicate the std dev.

since the attenuation was higher for the sensors further away from the source.

\section{DISCUSSION}

\subsection{AE signatures prior to failure}

The deformation and, consequently, the damage were concentrated in the WL where eventually the crack formed so that the sample failed completely. Therefore, we assume that the majority of the recorded $A E$ were generated in the $W L$ and carry information about the damage process. We identified several features in the AE signatures for the time preceding failure that seem indicative of the ongoing damage process. The energy rate and the mean inverse waiting time increased before failure implying an increase of the size and frequency of the AE events (Figs 8, 9a). We interpret the increase of size and frequency of the $\mathrm{AE}$ events as an acceleration of the damage process with increased size and frequency of damage and/or micro-cracks generating the AE.

The AE energy was power-law distributed indicating a scale invariance of the $\mathrm{AE}$ and the $b$-value decreased approaching failure (Fig. 7). The complementary cumulative distributions exhibited a significant curvature indicating a deviation from a power-law (Fig. 7), which may have multiple origins. According to Weiss (1997), the curvature may be due to the high attenuation of the acoustic waves, which has been shown for snow (Capelli and others, 2016).
An alternative reason may be that the $\mathrm{AE}$ energy distribution follows a truncated power-law with exponential cut-off, which is given by the finite size of the system. The observed decrease of the $b$-value could be due to a diverging cut-off approaching failure, which would result in an apparent $b$-value decrease (Amitrano and others, 2005; Alava and others, 2006; Girard and others, 2010). The goodness-of-fit of a truncated power-law will almost always be better compared with a simple power-law, since a function with two parameters can adapt better to the empirical data (Alstott and others, 2014). However, the use of a truncated powerlaw has two main disadvantages: (1) the additional parameter increases the complexity of the analysis, and (2) the identification of the exponential tail can be difficult due to the limited number of events used for the fit (Amitrano, 2012). The second problem could be mitigated by increasing the window size, causing, however, a decrease of the temporal resolution. Therefore, we used a simple power-law fit for the evaluations presented in this work, since the apparent decrease of the $b$-value provides a valid precursory pattern (Amitrano, 2012).

The decrease of the $b$-value corresponds to a change in the event distribution statistics and indicates that the portion of events with high energy increases before failure. A similar continuous decrease of the $b$-value was observed for the collapse of a rock cliff (Amitrano and others, 2005) and in numerical simulations of failure behavior (e.g.
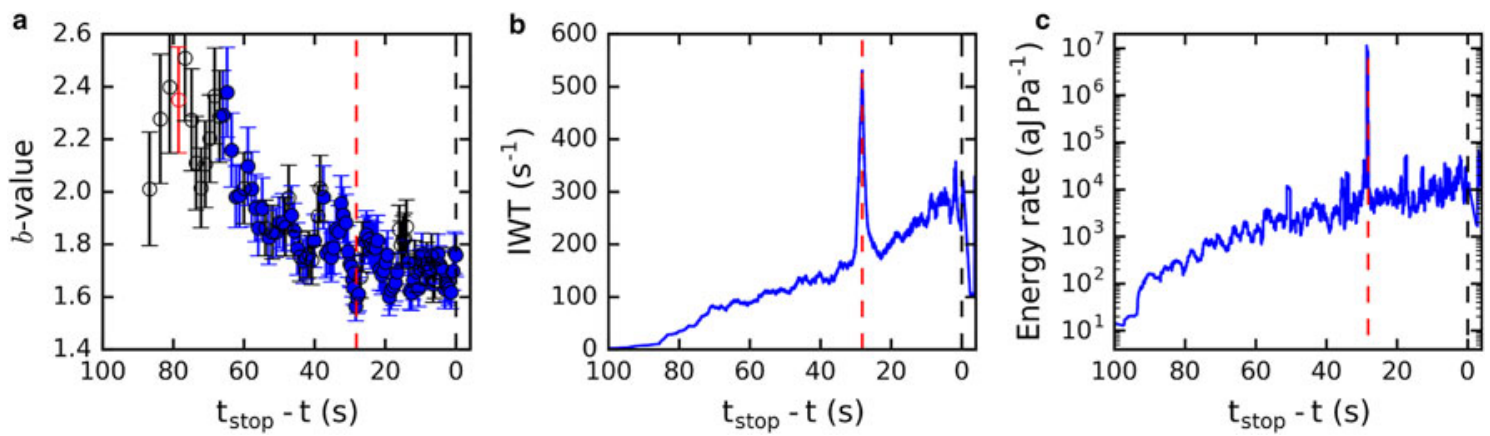

Fig. 15. Example of AE features in case of a local failure that did not lead to failure of the entire sample (LDL07B ch1; 168 Pa s ${ }^{-1}$ ). The local failure is marked by the red dashed vertical line at $28.2 \mathrm{~s}$. The sample reached the maximum load of $20 \mathrm{kPa}$ without failing. Evolution with time for (a) $b$-value (running window size $n=250$ hits, window separation 100 hits), (b) inverse waiting time (IWT) ( $n=300$ hits), (c) energy rate $(n=100$ hits). In the $b$-value evolution plot, the blue dots indicate that the power-law distribution provided the better fit than an exponential distribution; and vice versa for the red indicating that the exponential distribution yielded a better fit. The cases shown with open circles are those for which the goodness-of-fit was low and the model was not appropriate with $90 \%$ confidence $(P$-value $>0.1)$. The error bars indicate the std dev. 
Girard and others, 2010; Pradhan and others, 2010; Amitrano, 2012). A decrease of the $b$-value is often attributed to a transition from homogeneously distributed uncorrelated damage producing mostly small AE to larger correlated events, or in other words, to local stress concentrations causing localized damage (Johansen and Sornette, 2000; Girard and others, 2010). Although we do not have any direct proof of a change to localized and correlated damage before failure of snow, by analogy to other materials and numerical models, we assume that this change is likely taking place since we observed a feature, namely the decrease of $b$-value, which is often related to this transition from uncorrelated to localized damage leading to failure (Lockner, 1993; Guarino and others, 1998; Girard and others, 2010).

For snow, Reiweger and others (2015b) observed a drop in the $b$-value shortly before brittle fracture, whereas we observed a progressive decrease of the $b$-value. The experimental setup and the analysis method employed by Reiweger and others (2015b) were similar to those in our study, however, with the difference that our sample size was 10 times larger (basal area: $200 \mathrm{~cm}^{2}$ vs $2500 \mathrm{~cm}^{2}$ ). A decrease of the $b$-value coincident with brittle failure was also observed by Datt and others (2015) for samples of even smaller size $\left(\sim 35 \mathrm{~cm}^{2}\right)$. Therefore, we suggest that the observed difference in timing of the $b$-value decrease may be due to size effects. For small samples, the development of a major damage zone may quickly lead to complete failure of the sample. On the other hand, for large samples, the load may be redistributed allowing the progressive formation of several damage zones up to a critical point when finally the whole sample fails. This interpretation is supported by the observation of partial failures (Fig. 15). As in the case of the small samples, for the partial failures, the acceleration occurred on a short timescale compared with the duration of the experiment.

According to the theory of critical phenomena, the energy rate should diverge approaching failure following a powerlaw as was observed for load-controlled failure (Guarino and others, 1998; Amitrano and others, 2005) and for numerical simulations (e.g. Girard and others, 2010). Similarly, a divergence of the inverse waiting time was observed by Faillettaz and others (2011). In contrast, we observed an exponential increase of the energy rate and inverse waiting time without divergence at failure. In fact, an exponential increase was previously reported for displacement-controlled experiments (Guarino and others, 1998; Salminen and others, 2002). If the number of AE events per unit time is too high, the signals of distinct $\mathrm{AE}$ will be superimposed and measured as a single hit. This can explain the absence of the divergence in the waiting time. However, this is not true for the energy rate, since the much higher energy rate measured after failure shows that the maximum measurable energy rate was not reached before failure (see Fig. 8a). A possible explanation of our findings is that sintering (healing) counteracts the damage and hence inhibits the divergence toward failure.

\subsection{Rate-dependent behavior of snow and resulting AE features}

As expected, the deformation and failure behavior strongly depended on the loading rate. The strain at equal stress was much higher for the lowest loading rate and the majority of samples did not fail. The strain rate increased with increasing load for all loading rates. For example, as shown in Figure 6 , the strain rate for the experiments with the lowest loading rate increased to $4.5 \times 10^{-4} \mathrm{~s}^{-1}$ at a load of 13 $\mathrm{kPa}$, a value even higher than measured for the experiment with the highest loading rate. This finding suggests that the deformational behavior of the sample significantly changed with increasing load, presumably as consequence of damage accumulation and subsequent change in the snow microstructure.

Our results are in accordance with the previous experimental observations on the failure behavior as a function of loading rate (Narita, 1983; Schweizer, 1998; Reiweger and Schweizer, 2013). Schweizer and others (2003) reported a transition from ductile to brittle behavior at $\sim 10^{-3}$ to $10^{-4}$ $\mathrm{s}^{-1}$ for displacement-controlled shear experiments. However, we observed for the load-controlled experiments comparatively high strain rates at slow loading rates. Still, in our experiments, we did not observe brittle fracture due to experimental constraints, i.e. the maximum load was limited. These findings suggest that depending on the type of load, the strain rate alone is not sufficient to control the ductile-to-brittle transition, and that a more complex model is necessary to describe the snow failure behavior. As we observed that even at slow loading rates with ongoing damage process in the $\mathrm{WL}$ high strain rates may develop, we may argue that in combination with the inherent inhomogeneity of the snowpack, high stress rates may develop eventually leading to brittle fracture - and avalanche release.

The rate-dependent failure behavior of snow was also reflected in the $\mathrm{AE}$ emission signatures. The $b$-value decrease toward failure was lower for the lower loading rates with almost constant $b$-value for the lowest rate in the ductile range. The observed differences in the $b$-value evolution are in accordance with the observed difference between the ductile and brittle failure behavior and allow hypothesizing on the micromechanical origin of that difference in the failure behavior. The $b$-value decrease observed for the high loading rates can be interpreted as transition from homogeneously distributed uncorrelated damage to localized and correlated damage (causing larger AE events) occurring as the load increases. This transition eventually leads to brittle fracture of the entire sample. For the intermediate loading rate the transition was less pronounced. At the lower loading rates the $b$-value did not change indicating that the transition does not take place. We hypothesize that at the low loading rates, the damage process is compensated by the healing process, and the internal stresses can be redistributed by viscous deformation (Kirchner and others, 2001). Therefore, no transition was observed.

The energy rate depended on the loading rate as well. The exponential coefficient $\gamma_{\sigma}$ was similar for the two higher loading rates resulting in brittle fracture, while it was lower for the lowest loading rate. This indicates that the damage rate increase with increasing load was lower for the slower loading rate. Although the strain increase with increasing load was much higher for the slow loading rates, the energy rate at failure was similar or even lower to the energy rate measured for the experiments at the higher loading rates. Since we would expect a relation between strain and damage evolution, and hence higher AE activity for higher strain, the damage process at slow loading rates must be different from the one at high loading rates. A possible explanation is that during the experiments at low 
loading rates, the micro-cracks or local failures are smaller than at high loading rates, resulting in AE with smaller amplitude and higher wave frequency, since the frequency of acoustic waves is inversely related to the size of the source (e.g. Aki, 1967). However, this type of AE were not detected since the attenuation of acoustic waves in snow is high, in particular for high-frequency signals (Capelli and others, 2016). Higher frequency AE for slow experiments were observed by Scapozza and others (2004) for much smaller specimens, and were attributed to creep processes in the ice matrix.

For most of the samples loaded at slow loading rates, the AE signatures indicated that the damage process was for the entire duration of the experiment in a stable state, i.e. the damage process was likely compensated by the healing process (Fig. 14). On a shorter timescale, however, the $A E$ parameters varied suggesting that the damage process was not really constant but consisted of a sum of small bursts. We assume that the damage bursts were generated by cascades of correlated micro-cracks caused by localization of stresses at the microscale. However, the healing process inhibited the development of an unstable state through interaction of the small-scale damage and, therefore, the complete failure of the sample.

The above findings show that precursory features, which would allow the prediction of failure and are reported in the literature for other materials and models (e.g. Girard and others, 2010), were not present (divergence of energy rate and inverse waiting time at failure) in the $\mathrm{AE}$ signals we measured or that at slow loading rates failure may occur without precursors (decrease of $b$-value). Moreover, the described exponential increase of inverse waiting time and energy rate has just limited value for the identification of the failure point. This can be seen as a disadvantage for the application of $\mathrm{AE}$ to the snow stability assessment. However, the observed difference in the $A E$ signature in dependence of the loading rate may be used to investigate which of the two types of damage process we describe is involved in the formation of spontaneous avalanches, and may help to better understand as well as better model how the initial failures form that lead to avalanche release.

\section{CONCLUSIONS}

We developed a new apparatus that allows performing loadcontrolled snow failure experiments with large snow samples $\left(0.25 \mathrm{~m}^{2}\right)$ at different loading rates and simultaneously monitoring the AE generated during the failure process. The large sample size allowed us to investigate the interaction of cracks and accumulation of damage processes. We studied the influence of the loading rate on the AE signatures and interpreted the observed $\mathrm{AE}$ features in view of the damage process preceding complete fracturing of the sample.

For fast loading rate experiments, we observed a gradual decrease of the exponent of the AE energy distribution, i.e. the decrease of the $b$-value. This behavior can be interpreted based on the theory of critical phenomena as a transition from a stable state with uncorrelated AE events to an unstable state with correlated AE events leading to complete failure. Moreover, the energy rate and the waiting time increased exponentially prior to failure indicating an acceleration of the damage process.

The strongly loading rate-dependent behavior of snow was reflected in both the mechanical deformation of the samples prior to failure and the $\mathrm{AE}$ signatures. At high loading rates, we observed low strain and brittle fracture, whereas if loaded slowly, the samples exhibited high strain and mostly did not fail up to the maximum load of $20 \mathrm{kPa}$. At high loading rates, the AE response was characterized by a decreasing $b$-value and high energy rate increase, whereas at low loading rates, the $b$-value did almost not change and the energy rate increase was moderate. We deduce that during slow loading, the damage and healing processes were balanced preventing the complete failure. Although the AE parameters, when considering the entire duration of the experiment, indicated a stable state of the damage process, on a shorter timescale the $\mathrm{AE}$ parameters varied indicating an erratic damage process consisting of a sum of small bursts. We assume that these bursts were generated by cascades of correlated micro-cracks caused by the localization of stresses at the microscale $\left(\sim 1 \mathrm{~cm}^{2}\right)$. Most likely, the healing process (sintering and internal stress relaxation) prevented the development of an unstable state through interaction of this small-scale damage and, therefore, the complete failure of the sample.

Occasionally, we observed major local failures not leading to complete failure of the sample. The corresponding AE signatures differed from channel to channel, since signal attenuation was higher the further the sensors were from the failure zone. The occurrence of AE bursts, such as the observed local failure or the variations observed during the experiments at low loading rates, might allow identifying states with high probability of nucleating an initial failure that may eventually propagate and cause complete failure. To identify such unstable states, multiple sensors or distributed $\mathrm{AE}$ measurements may be required (e.g. Faillettaz and others, 2016). Therefore, future efforts should focus on the combined interpretation of the AE features of distributed sensors.

Our experimental results provide new insights into the failure behavior of snow in the context of interpreting the failure of disordered materials as critical phenomenon. Considering the disorder and its effect on failure behavior is crucial for advancing numerical modeling of snow failure - to eventually be incorporated by upscaling techniques into slab avalanche release models.

\section{ACKNOWLEDGEMENTS}

This project was funded by the Swiss National Science Foundation (SNF), project number 200021-146647. We thank Margaret Matzl for performing the CT scans and Marco Collet and the SLF workshop team for the planning and construction of the loading apparatus. We thank the editor Nicolas Eckert and the anonymous reviewers for the numerous suggestions that helped to improve the paper.

\section{REFERENCES}

Aki K (1967) Scaling law of seismic spectrum. J. Geophys. Res., 72 (4), 1217-1231

Alava MJ, Nukalaz PKVV and Zapperi S (2006) Statistical models of fracture. Adv. Phys., 55(3-4), 349-476

Alstott J, Bullmore E and Plenz D (2014) Powerlaw: a python package for analysis of heavy-tailed distributions. PLOS ONE, 9 (1), e85777

Amitrano D (2012) Variability in the power-law distributions of rupture events - how and why does b-value change. Eur. Phys. J. Spec. Top., 205(1), 199-215 
Amitrano D and Helmstetter A (2006) Brittle creep, damage, and time to failure in rocks. J. Geophys. Res. Solid Earth, 111(B11)

Amitrano D, Grasso JR and Senfaute G (2005) Seismic precursory patterns before a cliff collapse and critical point phenomena. Geophys. Res. Lett., 32(8), L08314

Bowles D and St. Lawrence WF (1977) Acoustic emissions in the investigation of avalanches. Proceedings of the 45th Annual Western Snow Conference, Albuquerque, NM, USA, 18-21 April 1977, 88-94

Bucur V (2006) Acoustics of wood, 2nd edn. Springer: Berlin, Germany

Capelli A, Kapil JC, Reiweger I, Or D and Schweizer J (2016) Speed and attenuation of acoustic waves in snow: laboratory experiments and modelling with Biot's theory. Cold Reg. Sci. Technol., 125, 1-11

Clauset A, Shalizi CR and Newman MEJ (2009) Power-law distributions in empirical data. SIAM Rev., 51(4), 661-703

Datt P, Kapil JC and Kumar A (2015) Acoustic emission characteristics and $b$-value estimate in relation to waveform analysis for damage response of snow. Cold Reg. Sci. Technol., 119, 170-182

de Montmollin V (1982) Shear tests on snow explained by fast metamorphism. J. Glaciol., 28(98), 187-198

Faillettaz J, Funk M and Sornette D (2011) Icequakes coupled with surface displacements for predicting glacier break-off. J. Glaciol., 57(203), 453-460

Faillettaz J, Or D and Reiweger I (2016) Codetection of acoustic emissions during failure of heterogeneous media: new perspectives for natural hazard early warning. Geophys. Res. Lett.

Fierz C and 8 others (2009) The international classification for seasonal snow on the ground. UNESCO-IHP, Paris, France

Fukuzawa T and Narita H (1993) An experimental study on the mechanical behavior of a depth hoar under shear stress. Proceedings ISSW 1992. International Snow Science Workshop, Breckenridge, Colorado, USA, 4-8 October 1992, Colorado Avalanche Information Center, Denver CO, USA, 171-175

Gaume J, van Herwijnen A, Chambon G, Birkeland KW and Schweizer J (2015) Modeling of crack propagation in weak snowpack layers using the discrete element method. Cryosphere, 9, 1915-1932

Girard L, Amitrano D and Weiss J (2010) Failure as a critical phenomenon in a progressive damage model. J. Stat. Mech. Theory Exp., 2010(01), P01013

Grosse CU and Ohtsu M (2008) Acoustic emission testing. Springer, Berlin Heidelberg, Germany

Guarino A, Garcimartin A and Ciliberto S (1998) An experimental test of the critical behaviour of fracture precursors. Eur. Phys. J. B, 6(1), 13-24

Gubler $\mathrm{H}$ (1979) Acoustic emission as an indication of stability decrease in fracture zones of avalanches. J. Glaciol., 22(86), 186-188

Hagenmuller P, Theile TC and Schneebeli M (2014) Numerical simulation of microstructural damage and tensile strength of snow. Geophys. Res. Lett., 41(1), 86-89

Johansen A and Sornette D (2000) Critical ruptures. Eur. Phys. J. B, 18(1), 163-181

Kalman RE (1960) A new approach to linear filtering and prediction problems. J. Basic Eng., 82(1), 35-45

Kirchner HOK, Michot G, Narita H and Suzuki T (2001) Snow as a foam of ice: plasticity, fracture and the brittle-to-ductile transition. Philos. Mag. A, 81(9), 2161-2181

Lockner D (1993) The role of acoustic-emission in the study of rock fracture. Int. J. Rock Mech. Min. Sci., 30(7), 883-899

Lynch KP and Scarano F (2014) Experimental determination of tomographic PIV accuracy by a 12-camera system. Meas. Sci. Technol., 25(8), 084003

Narita H (1983) An experimental study on tensile fracture of snow. Contrib. Inst. Low Temp. Sci., A32, 1-37

Nechad H, Helmstetter A, El Guerjouma R and Sornette D (2005) Creep ruptures in heterogeneous materials. Phys. Rev. Lett., 94(4), 045501
Ohtsu M (1996) The history and development of acoustic emission in concrete engineering. Mag. Concr. Res., 48(177), 321-330

Pradhan S, Hansen A and Chakrabarti BK (2010) Failure processes in elastic fiber bundles. Rev. Mod. Phys., 82(1), 499-555

Reiweger I and Schweizer J (2013) Weak layer fracture: facets and depth hoar. Cryosphere, 7(5), 1447-1453

Reiweger I, Schweizer J, Dual J and Herrmann HJ (2009) Modelling snow failure with a fiber bundle model. J. Glaciol., 55(194), 9971002

Reiweger I, Schweizer J, Ernst R and Dual J (2010) Load-controlled shear apparatus for snow. Cold Reg. Sci. Technol., 62(2-3), $119-125$

Reiweger I, Gaume J and Schweizer J (2015a) A new mixed-mode failure criterion for weak snowpack layers. Geophys. Res. Lett., 42(5), 1427-1432

Reiweger I, Mayer K, Steiner K, Dual J and Schweizer J (2015b) Measuring and localizing acoustic emission events in snow prior to fracture. Cold Reg. Sci. Technol., 110, 160-169

Salminen LI, Tolvanen AI and Alava MJ (2002) Acoustic emission from paper fracture. Phys. Rev. Lett., 89(18), 185503

Scapozza C, Bucher F, Amann P, Ammann WJ and Bartelt P (2004) The temperature- and density-dependent acoustic emission response of snow in monoaxial compression tests. Ann. Glaciol., 38, 291-298

Schleef S, Jaggi M, Löwe H and Schneebeli M (2014) An improved machine to produce nature-identical snow in the laboratory. J. Glaciol., 60(219), 94-102

Schneebeli M and Johnson JB (1998) A constant-speed penetrometer for high-resolution snow stratigraphy. Ann. Glaciol., 26, 107-111

Schneebeli M and Sokratov SA (2004) Tomography of temperature gradient metamorphism of snow and associated changes in heat conductivity. Hydrol. Processes, 18(18), 3655-3665

Schweizer J (1998) Laboratory experiments on shear failure of snow. Ann. Glaciol., 26, 97-102

Schweizer J (1999) Review of dry snow slab avalanche release. Cold Reg. Sci. Technol., 30(1-3), 43-57

Schweizer J, Jamieson JB and Schneebeli M (2003) Snow avalanche formation. Rev. Geophys., 41(4), 1016

Schweizer J, Kronholm K, Jamieson JB and Birkeland KW (2008) Review of spatial variability of snowpack properties and its importance for avalanche formation. Cold Reg. Sci. Technol., 51(2-3), 253-272

Schweizer J, Reuter B, van Herwijnen A and Gaume J (2016) Avalanche release 101. In Greene E, ed. Proceedings ISSW 2016. International Snow Science Workshop, Breckenridge, CO, USA, 3-7 October 2016, 1-11

Sommerfeld RA (1977) Preliminary observations of acoustic emissions preceding avalanches. J. Glaciol., 19(81), 399-409

Sommerfeld RA (1982) A review of snow acoustics. Rev. Geophys. Space Phys., 20(1), 62-66

Sommerfeld RA and Gubler H (1983) Snow avalanches and acoustic emissions. Ann. Glaciol., 4, 271-276

St. Lawrence WF (1980) The acoustic emission response of snow. J. Glaciol., 26(94), 209-126

St. Lawrence WF and Bradley CC (1977) Spontaneous fracture initiation in mountain snow-packs. J. Glaciol., 19(81), 411-417

van Herwijnen A (2013) Experimental analysis of snow micropenetrometer (SMP) cone penetration in homogeneous snow layers. Can. Geotech. J., 50(10), 1044-1054

Watters RJ and Swanson K (1987) Sensor frequency, wave guide orientation and type, and their influence on acoustic emission monitoring of snow pack stability. Proceedings ISSW 1986. International Snow Science Workshop, Lake Tahoe, California, USA, 22-25 October 1986, ISSW Workshop Committee, Homewood, CA, USA, 81-85

Weiss J (1997) The role of attenuation on acoustic emission amplitude distributions and b-values. Bull. Seismol. Soc. Am., 87(5), 1362-1367 